end of the study, the treatment has efficacy even if 1 or 2 yrs have elapsed since the patient stops treatment. To date, there is no convincing evidence to support such an assumption. Unknown usual care treatment for withdrawals including ICS could further bias the results. Thus, for short-term secondary outcomes (e.g. exacerbations) the intention-to-treat analysis might not produce robust and meaningful results. Estimating and correcting for regression towards the mean could help in achieving clinically more reliable results.

In addition, AARON et al. [6] argue elsewhere that premature termination of a drug, for whatever reason (including withdrawal of informed consent), might indicate both impaired tolerance and lack of efficacy. Thus, regarding the end-point withdrawal as just another measure of effectiveness. Effectiveness, however, is not the efficacy of a drug in a randomised controlled trial, but in the real life medical care situation, which may be quite different.

Therefore the correct statistical methodology might be complex and would require many variables to be considered: the population studied; duration of the study; data on recent and subsequent treatment in patients who discontinued prematurely; characteristics of the treatment; and properties of the outcome variable.

In conclusion, as a clinician I agree with SuISSA et al. [1] that rigorous study design and conservative assessment are urgently needed to avoid spurious results when studying drug treatment in chronic obstructive pulmonary disease. Particularly in exacerbation trials the bias that might arise from inhaled corticosteroids pre-treatment and withdrawal should be accounted for (even if we assume it does not necessarily confuse the effect in every case). The continued evolution of statistics and our knowledge of the complex disease chronic obstructive pulmonary disease might allow better clinical and statistical assessment of the population, the drug under investigation, the treatment effects and withdrawals in each study. So far it appears no "one size fits all" method is readily available.

\section{P. Kardos}

Group Practice and Centre for Respiratory Medicine, Allergy and Somnology at Maingau Hospital, Frankfurt am Main, Germany.

\section{STATEMENT OF INTEREST}

A statement of interest for P. Kardos can be found at www.erj.ersjournals.com/misc/statements.shtml

\section{REFERENCES}

1 Suissa S, Ernst P, Vandemheen KL, Aaron SD. Methodological issues in therapeutic trials of COPD. Eur Respir J 2008; 31: 927-933.

2 Kardos P, Wencker M, Glaab T, Vogelmeier C. Impact of salmeterol/fluticasone propionate versus salmeterol on exacerbations in severe chronic obstructive pulmonary disease. Am J Respir Crit Care Med 2007; 175: 144-149.

3 Calverley PM, Anderson JA, Celli B, et al. Salmeterol and fluticasone propionate and survival in chronic obstructive pulmonary disease. N Engl J Med 2007; 356: 775-789.

4 Wedzicha JA, Calverley PMA, Seemungal TA, et al. The prevention of chronic obstructive pulmonary disease exacerbations by salmeterol/fluticasone propionate or tiotropium bromide. Am J Respir Crit Care Med 2008; 177: 19-26.

5 Ernst P, Gonzalez AV, Brassard P, Suissa S. Inhaled corticosteroid use in COPD and the risk of hospitalization for pneumonia. Am J Respir Crit Care Med 2007; 176: 162-166.

6 Aaron SD, Fergusson D, Marks GB, et al. Counting, analysing and reporting exacerbations of COPD in randomised controlled trials. Thorax 2008; 63: 122-128.

7 Cooper CB, Decramer M. Inhaled steroids and COPD. Eur Respir J 2008; 32: 523-524.

\title{
Inhaled insulin does not trigger lung inflammation and airway remodelling
}

\section{To the Editors:}

We read with great interest the paper by LIU et al. [1], regarding the effects of inhaled insulin on airway lining fluid composition in adults with diabetes. The study concluded that treatment with inhaled human insulin (Exubera ${ }^{\circledR}$ ) is not associated with evidence of pulmonary inflammation and therefore the treatment effects on lung function observed in Exubera ${ }^{\circledR}$ trials are not caused by lung inflammation.

Local inflammation results in airway remodelling mediated by cytokines produced by recruited inflammatory cells, as well as by airway myofibroblasts and airway smooth muscle (ASM) cells [2]. ASM cells maintain their plasticity exhibiting a differentiated contractile or a synthetic proliferative phenotype in response to physiological and pathological signals [3]. In a relevant study, we examined the possibility that growthpromoting properties of inhaled insulin play a role in airway remodelling [4]. Our findings regarding insulin's effect on rabbit tracheal ASM cell proliferation, show that insulin transiently promotes cell proliferation in ASM cells by the activation of the phosphoinositide 3-kinases. Importantly, longer incubation with insulin didn't lead to additional cell growth.

Therefore, the in vivo study by LiU et al. [1] together with our in vitro study [4] suggest that long-term exposure of the airways to insulin, as in the administration of inhaled insulin in 
patients with diabetes mellitus, is not likely a risk factor for inflammation and airway remodelling.

M. Papagianni*, A. Hatziefthimiou*, G. Chachami*, K. Gourgoulianis", P-A. Molyvdas* and E. Paraskeva* *Depts of Physiology and "Respiratory Medicine, Medical School, University of Thessaly, Larissa, Greece.

\section{STATEMENT OF INTEREST}

None declared.

\section{REFERENCES}

1 Liu MC, Riese RJ, Van Grundy K, et al. Effects of inhaled human insulin on airway lining fluid composition in adults with diabetes. Eur Respir J 2008; 32: 180-188.
2 Halayko AJ, Amrani Y. Mechanisms of inflammationmediated airway smooth muscle plasticity and airway remodeling in asthma. Respir Physiol Neurobiol 2003; 137: 209-222.

3 Halayko AJ, Solway J. Plasticity in skeletal, cardiac, and smooth muscle: invited review: molecular mechanisms of phenotypic plasticity in smooth muscle cells. J Appl Physiol 2001; 90: 358-368.

4 Papagianni M, Hatziefthimiou A, Chachami G, Gourgoulianis K, Molyvdas P-A, Paraskeva E. Insulin causes a transient induction of proliferation via activation of the PI3-kinase pathway in airway smooth muscle cells. Exp Clin Endocrinol Diabetes 2007; 115: 118-123.

\section{Palliative and end-of-life care for patients with severe COPD}

\section{To the Editors:}

We congratulate CURTIS [1] on his excellent review on the very important and under-recognised topic of palliation in endstage chronic obstructive pulmonary disease (COPD). We agree that the use of noninvasive ventilation (NIV) as palliation may be impractical in the hospice environment, and that NIV should not be used first-line for the palliation of breathlessness in COPD. However, we do not think that there is sufficient recognition that in certain specific circumstances NIV may have a role in end-stage COPD.

First, as clearly stated, prognostication is exceedingly difficult in advanced COPD, and deciding if an exacerbation is likely to be recoverable or not is problematic. With acute exacerbations, more than half of patients with advanced COPD who have a "do-not-intubate" order, but receive NIV, live to hospital discharge [2]. Therefore, providing it is in accordance with the patient's wishes and in the context of hospital admission for acute hypercapnic respiratory failure, we would advocate a trial of NIV in patients who are deemed "not for invasive ventilation".

Secondly, despite the lack of supportive evidence from the current literature for the routine use of NIV as a palliative measure in advanced COPD, we would argue that in carefully selected patients in appropriately resourced environments with trained staff, there is no harm in a trial of NIV if there is the potential for significant symptomatic benefit [3]. Benefits of palliative NIV include: relief of breathlessness; ability to enable sleep; and "buying time" to ascertain patients' wishes. In the UK, patients with COPD may be admitted to hospitals unaccompanied and without casenotes, NIV is often started pending information on pre-morbid status. Furthermore, although it is best practice to ascertain a patient's wishes regarding treatment/resuscitation in advance, in practice this rarely occurs [1].

We agree with the importance of early discussion regarding the risks and benefits of noninvasive and invasive ventilation [1]. However, it would not be in a patient's best interests to offer a therapeutic option that is unlikely to be available. In intensive care units in the UK, patients with end-stage chronic obstructive pulmonary disease would be unlikely to be accepted for invasive ventilation. Furthermore, no clinician is obliged to provide an intervention that they do not believe is in the best interests of the patient. At least in the UK, this seldomdiscussed dilemma may be a factor inhibiting physicians from full and frank discussion of end-of-life issues.

\section{B.C. Creagh-Brown* and C. Shee}

*Adult Intensive Care Unit, Royal Brompton Hospital, London, and "Dept of Respiratory Medicine, Queen Mary's Hospital, Sidcup, UK.

\section{STATEMENT OF INTEREST}

None declared.

\section{REFERENCES}

1 Curtis JR. Palliative and end-of-life care for patients with severe COPD. Eur Respir J 2008; 32: 796-803.

2 Creagh-Brown B, Shee C. Noninvasive ventilation as ceiling of therapy in end-stage chronic obstructive pulmonary disease. Chron Respir Dis 2008; 5: 143-148. 